\title{
PEMBUATAN POIN PENILAIAN DAN TARGET PADA PERSPEKTIF BALANCED SCORECARD SEBAGAI TOLAK UKUR PENGUKURAN KINERJA
}

\author{
Daniel Agung, S.Tr. ${ }^{(1)}$, Dr. Ir. Zulfa Fitri Ikatrinasari, M.T. ${ }^{(2)}$ \\ ${ }^{1}$ Magister Teknik Industri / Universitas Mercu Buana / danielagung0508@gmail.com \\ ${ }^{2}$ Magister Teknik Industri / Universitas Mercu Buana / zulfafitri@gmail.com
}

\begin{abstract}
Performance measurement is a very important thing for the company. With the performance measurement, it will be known where the company position and can be used to evaluate and make improvements. Good performance measurement is a performance measurement that can represent the performance of the whole company, therefore used the Balanced Scorecard as a performance measurement method that can evaluate the overall performance of the company. In the Balanced Scorecard there are 4 perspectives that are used as performance measurement benchmarks, namely financial perspective, customer perspective, internal business process perspective, and employee learning and growth perspective. Balance Scorecard measurement is done based on vision, mission, strategy and KPI from BCD company and Moldmaker department. Based on the results of the analysis conducted, obtained some points that become benchmarks of performance based on each existing perspective, among others: (1) Financial Perspective: Profit Loss per Project, Back Log Project, Order Intake, Sales; (2) Customer Perspective: OTD T0 \& OTD Sales; (3) Internal business process perspective: Utilization, Non Quality Cost, Overtime; (4) Employee learning and growth perspective: Training Employee (Technical), Training Employee (Non Technical), Turn Over Rate, Head Count Personnel.
\end{abstract}

Keywords : Balance Scorecard, performance, Moldmaker

\begin{abstract}
ABSTRAK
Pengukuran kinerja merupakan suatu hal yang sangat penting bagi perusahaan. Dengan adanya pengukuran kinerja, akan diketahui dimana posisi perusahaan dan dapat digunakan untuk mengevaluasi serta melakukan perbaikan. Pengukuran kinerja yang baik adalah pengukuran kinerja yang dapat mewakili kinerja dari keseluruhan perusahaan, maka dari itu digunakan Balanced Scorecard sebagai metode pengukuran kinerja yang dapat mengevaluasi keseluruhan kinerja dari perusahaan. Dalam Balanced Scorecard terdapat 4 perspektif yang digunakan sebagai tolak ukur pengukuran kinerja, yaitu perspektif finansial, perspektif pelanggan, perspektif proses bisnis internal, dan perspektif pembelajaran dan pertumbuhan karyawan. Pengukuran Balance Scorecard dilakukan berdasarkan visi, misi, strategi dan KPI dari perusahaan BCD dan departemen Moldmaker. Berdasarkan hasil analisa yang dilakukan, didapat beberapa poin yang menjadi tolak ukur kinerja berdasarkan setiap perspektif yang ada, antara lain : ( 1 ) Perspektif finansial : Profit Loss per Project, Back Log Project, Order Intake, Sales ; ( 2 ) Perspektif pelanggan : OTD T0 \& OTD Sales ; ( 3 ) Perspektif proses bisnis internal : Utilization, Non Quality Cost, Overtime ; ( 4 ) Perspektif pembelajaran dan pertumbuhan karyawan : Training Employee ( Technical ), Training Employee ( Non Technical ), Turn Over Rate, Head Count Personnel.
\end{abstract}

Kata Kunci : Balance Scorecard, kinerja, Moldmaker 


\section{PENDAHULUAN}

Era globalisasi saat ini, mendorong meningkatnya daya saing dari setiap perusahaan untuk dapat terus beradaptasi terhadap perubahan yang terjadi. Selain itu, dibutuhkan juga konsep manajemen pengukuran kinerja yang baik untuk mengetahui posisi dari perusahaan dan gambaran strategi yang dapat dikembangkan di masa yang akan datang. Untuk dapat bertahan dan beradaptasi dengan perubahan yang terus terjadi, dibutuhkan suatu metodologi penilaian kinerja yang berorientasi pada pandangan strategis ke masa depan dan mudah untuk dikomunikasikan kepada pengguna akhir, yang dalam hal ini merupakan karyawan yang akan melaksanakan rencana- rencana strategis yang telah dibuat perusahaan. Komunikasi antara manajemen organisasi dan karyawan itu adalah Balanced Scorecard. Pengukuran kinerja yang efektif akan mampu menilai seluruh perspektif perusahaan dimana seluruh perspektif itu akan tertuang di dalam Balanced Scorecard.

Pengukuran kinerja dengan menggunakan Balanced Scorecard menggambarkan kinerja jangka pendek dan jangka panjang, keuangan dan non keuangan, internal dan eksternal. Balanced Scorecard merupakan sistem pengukuran komprehensif dari berbagai aspek, baik itu dari segi keuangan dan non keuangan, maupun aset yang tampak dan tak tampak. Pengukuran kinerja dengan pendekatan Balanced Scorecard digunakan oleh perusahaan atau organisasi berdasarkan visi dan misi organisasi ( Ancella, 1996 ). Pengukuran kinerja dengan pendekatan Balanced Scorecard tidak hanya sebagai sistem pengukuran saja, tetapi dapat berfungsi sebagai sistem pengukuran yang baru untuk mengkomunikasikan dan menghubungkan suatu organisasi kepada strategi baru ( Kaplan \& Norton, 2000 ) .

Departemen Moldmaker merupakan departemen yang bertanggung jawab untuk membuat dan menghasilkan cetakan plastik ( mold) yang akan digunakan untuk produksi produk berbahan plastik. Departemen Moldmaker membuat cetakan plastik dimulai dari proses desain, proses pemesinan dan proses perakitan. Departemen Moldmaker akan bertanggung jawab terhadap kualitas cetakan plastik saat proses trial sampai produk yang dihasilkan sudah disetujui oleh konsumen. Konsumen internal dari departemen Moldmaker adalah departemen Research \& Development ( R \& D ). Cetakan plastik yang telah selesai dirakit akan diuji bersama- sama dengan departemen Research \& Development sampai dihasilkan produk yang disetujui konsumen, barulah cetakan plastik tersebut akan terhitung sebagai hasil penjualan internal departemen Moldmaker. Saat ini departemen Moldmaker hanya berorientasi terhadap kepuasan pelanggan, dimana hanya berpatokan terhadap target waktu trial yang sudah ditetapkan departemen Research \& Development, dan belum berorientasi secara integrasi seperti pada metode Balanced Scorecard. Saat ini, departemen Moldmaker tidak dihitung sebagai Profit Center perusahaan dan dihitung sebagai departemen penunjang dimana cetakan plastik yang dihasilkan juga akan dijual secara internal ke departemen produksi dan biaya pembuatan mold akan dibayar oleh konsumen beserta produk yang dihasilkan. Target perusahaan adalah ingin memperhitungkan departemen Moldmaker sebagai Profit Center, sehingga pengukuran kinerja dengan menggunakan Balanced Scorecard benar- benar diperlukan untuk mengintegrasikan berbagai perspektif sehingga dapat dilakukan analisa dan perbaikan yang tepat sasaran. Penelitian ini menentukan poin- poin penilaian apa saja dan target yang dijadikan tolak ukur pengukuran kinerja di departemen Moldmaker berdasarkan dengan perspektif yang digunakan pada metode Balanced Scorecard.

\section{STUDI LITERATUR}

\subsection{Pengukuran kinerja}

Kinerja merupakan gambaran mengenai tingkat pencapaian pelaksanaan suatu program kegiatan atau kebijakan dalam mewujudkan sasaran, tujuan, visi dan misi organisasi yang dituangkan melalui perencanaan strategis suatu organisasi. Pengukuran kinerja merupakan gambaran mengenai tingkat pencapaian pelaksanaan suatu program kegiatan dalam 
mewujudkan sasaran, tujuan, visi dan misi organisasi yang dituangkan melalui perencanaan strategis suatu organisasi. Tujuan pokok penilaian kerja adalah untuk memotivasi karyawan dalam mencapai tujuan organisasi dan dalam mencapai tujuan organisasi dan dalam mematuhi standar perilaku yang telah ditetapkan sebelumnya agar membuahkan tindakan dan hasil yang diinginkan.

\subsection{Balanced Scorecard}

Konsep Balanced Scorecard diperkenalkan oleh Robert S. Kaplan dan David P. Norton, dimana menurut Gasperz ( 2008 ), dengan menggunakan Balanced Scorecard, rencanarencana bisnis strategis akan mencapai setiap orang dalam organisasi, karena semua orang dalam organisasi telah memiliki alat komunikasi ( bahasa ) yang sama. Apabila rencanarencana strategis bisnis itu dinyatakan dalam bentuk pengukuran dan target, karyawan dapat mengerti dan mengaitkan dengan apa yang akan terjadi. Hal ini akan mengarah pada pelaksanaan rencana- rencana strategis yang lebih baik. Terdapat empat perspektif Balanced Scorecard yang dikaitkan dengan visi dan strategi organisasi, yaitu : ( 1 ) perspektif finansial ( shareholders- pemegang saham ), ( 2 ) perspektif pelanggan ( customers ), ( 3 ) perspektif proses bisnis internal ( internal-business-process ), ( 4 ) perspektif pembelajaran dan pertumbuhan karyawan, manajemen, dan organisasi ( learning and growth ). Visi, misi, strategi dan KPI ( Key Performance Indicators ) organisasi maupun departemen dikaitkan secara seimbang dengan perspektif finansial, perspektif pelanggan, perspektif proses bisnis internal, dan perspektif pembelajaran dan pertumbuhan. Balanced Scorecard memberi manajemen organisasi suatu pengetahuan, keterampilan, dan sistem yang memungkinkan karyawan dan manajemen belajar dan berkembang terus- menerus ( perspektf pembelajaran dan pertumbuhan ) dalam berinovasi untuk membangun kapabilitas strategis yang tepat serta efisiensi ( perspektif proses bisnis internal ) agar mampu menyerahkan nilai spesifik ke pasar ( perspektif pelanggan ) dan selanjutnya mengarah pada nilai saham yang terus- menerus meningkat ( perspektif finansial ). Berdasarkan gambar 1, dapat dilihat bahwa keempat perspektif yang ada berasal dari visi dan strategi yang perusahaan inginkan, sehingga salah 1 pekerjaan yang harus dilakukan adalah menetapkan visi dan strategi yang ambisius untuk dapat diterapkan dan diukur menggunakan Balanced Scorecard.

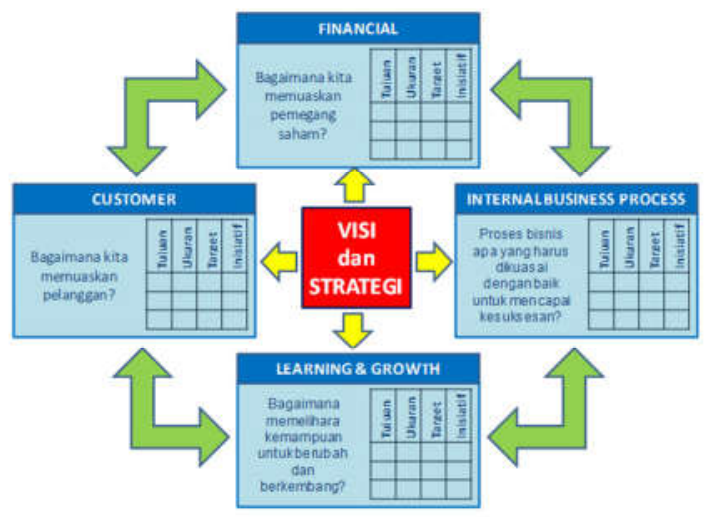

\section{Gambar 1. Balanced Scorecard sebagai suatu Sistem Manajemen Kinerja ( Sumber : Kaplan \& Norton, 1996 )}

\subsection{Perspektif dalam Balanced Scorecard}

Seperti pada pembahasan sebelumnya, dalam Balanced Scorecard terdapat 4 perspektif yaitu perspektif finansial, perspektif pelanggan, perspektif proses bisnis internal, dan perspektif pembelajaran dan pertumbuhan karyawan. Kaplan dan Norton ( 1992 ) memperkenalkan 4 
perspektif yang berbeda dari suatu aktivitas perusahaan yang dapat dievaluasi oleh manajemen, sebagai berikut :

1. Perspektif finansial - bagaimana kita memuaskan pemegang saham ?

2. Perspektif pelanggan - bagaimana kita memuaskan pelanggan ?

3. Perspektif proses bisnis internal - apa proses- proses yang seyogianya diinginkan untuk mencapai kesuksesan perusahaan?

4. Perspektif pembelajaran dan pertumbuhan karyawan - bagaimana kita akan mempertahankan keberlangsungan kemampuan terhadap perubahan dan peningkatan?

Perspektif finansial dimana tujuan finansial berperan sebagai fokus bagi tujuan- tujuan strategis dan ukuran- ukuran semua perspektif dalam Balanced Scorecard. Segala ukuran yang dipilih harus menjadi bagian dari suatu keterkaitan hubungan sebab akibat yang memuncak pada peningkatan kinerja finansial. Ketika mendefinisikan nilai dalam perspektif finansial, pemegang saham haris mempertimbangkan tahapan-tahapan dalam siklus hidup bisnis, yang pada dasarnya dibagi ke dalam 3 tahap, yaitu : ( 1 ) perusahaan yang berada pada tahap awal pertumbuhan, ( 2 ) perusahaan yang berada pada tahap keberlangsungan, dan ( 3 ) perusahaan yang berada pada tahap kematangan. Pemahaman akan perspektif finansial merupakan hal yang sangat penting karena keberlangsungan suatu unit bisnis strategis sangat tergantung pada posisi dan kekuatan finansial. Manajemen bisnis harus memperhatikan agar semua analisis rasio finansial menunjukkan hasil yang baik.

Perspektif pelanggan dalam Balanced Scorecard akan mempertimbangkan proses identifikasi dari pelanggan dan segmen pasar di mana mereka akan berkompetisi. Elemen yang paling penting dalam suatu bisnis adalah kebutuhan pelanggan. Dalam penelitian ini, pelanggan yang dimaksud adalah pelanggan internal atau departemen terkait di dalam perusahaan, sehingga dibutuhkan komunikasi yang baik dan terintegrasi supaya dapat memenuhi kebutuhan pelanggan.

Perspektif proses bisnis internal di dalam Balanced Scorecard mengharuskan manajer untuk mengidentifikasi proses- proses yang paling kritis untuk mencapai tujuan peningkatan nilai bagi pelanggan ( perspektif pelanggan ) dan tujuan peningkatan nilai bagi pemegang saham ( perspektif finansial ). Model rantai proses bisnis internal yang sering digunakan terdiri dari 3 komponen utama, yaitu : ( 1 ) Proses inovasi, ( 2 ) Proses operasional, ( 3 ) Proses pelayanan. Proses inovasi merupakan proses dimana mengidentifikasi kebutuhan pelanggan masa kini dan masa mendatang serta mengembangkan solusi baru untuk kebutuhan pelanggan itu. Proses operasional merupakan proses untuk mengidentifikasi sumber- sumber pemborosan dalam proses operasional serta mengembangkan solusi masalah yang terdapat dalam proses operasional itu demi meningkatkan efisiensi produksi, meningkatkan kualitas produk dan proses, memperpendek waktu siklus ( cycle time ) sehingga meningkatkan penyerahan produk berkualitas tepat waktu. Proses pelayanan berkaitan dengan pelayanan kepada pelanggan, seperti : menyelesaikan masalah yang timbul pada pelanggan dalam waktu cepat, melakukan tindak lanjut secara proaktif dan tepat waktu, dll.

Perspektif pembelajaran dan pertumbuhan mengembangkan tujuan dan ukuran- ukuran yang mengendalikan pembelajaran dan pertumbuhan organisasi. Tujuan- tujuan yang ditetapkan dalam perspektif finansial, pelanggan, dan proses bisnis internal mengidentifikasi di mana organisasi harus unggul untuk mencapai terobosan kinerja, sementara tujuan dalam perspektif pembelajaran dan pertumbuhan memberikan infrastruktur yang memungkinkan tujuantujuan ambisius dalam ketiga perspektif lainnya tercapai.

\section{METODOLOGI PENELITIAN}

Metodologi penelitian yang digunakan dalam mengumpulkan data dan informasi yang dibutuhkan adalah metode historis analis, yaitu metode yang digunakan dengan mengumpulkan data dan informasi berdasarkan data di masa lampau yang digunakan sebagai 
acuan untuk analisa di masa sekarang. Sumber data yang digunakan adalah sumber data internal dan sumber data sekunder, yaitu sumber data yang digunakan didapat dari dalam perusahaan dan sumber data diperoleh secara tidak langsung melalui media perantara berupa data yang sudah diolah sebelumnya dan sudah berbentuk dokumen.

\section{HASIL DAN PEMBAHASAN}

Penelitian ini akan merumuskan keempat poin perspektif pada Balanced Scorecard berdasarkan data di masa lampau yang kemudian dianalisa dan dijadikan sebagai patokan penilaian oleh pemegang saham di masa sekarang. Poin dan target dalam Balanced Scorecard mengacu terhadap Visi, misi, strategi dan KPI ( Key Performance Indicators ) perusahaan serta departemen terkait, dalam hal ini departemen Moldmaker. Berikut visi, misi, strategi, dan KPI perusahaan BCD dan departemen Moldmaker :

Visi :

Menjadi Produsen Kemasan Plastik Nomor 1 di Indonesia yang Dihormati dan Diakui oleh Konsumen-konsumen Utama.

Misi :

1. Fokus membangun organisasi bersama Pemimpin-pemimpin terpercaya yang berkomitmen pada kesempurnaan

2. Memastikan kepuasan konsumen dengan kualitas produk yang konsisten \& disampaikan tepat waktu melalui hubungan kerjasama yang erat didukung pemasok berdedikasi

3. Mendorong kerjasama tim lintas fungsi dengan sistem, proses dan pengukuran kinerja yang terintegrasi

4. Mengupayakan perbaikan berkelanjutan dari setiap karyawan berlandaskan nilai-nilai inti perusahaan

\section{Strategi :}

1. Meraih Pelanggan Potensial

2. Produksi produk yang memenuhi standard kualitas konsumen

3. Total Efisiensi Manufaktur

4. Pengiriman Tepat Waktu

5. Meningkatkan kompetensi karyawan

\section{Target Manajemen :}

Menjadikan Moldmaker sebagai profit center

\section{KPI Departemen :}

Tabel 1. KPI Departemen Moldmaker

\begin{tabular}{|l|l|}
\hline Quality PDS Final (max 3x) & $100 \%$ \\
\hline Mold Cost Budget vs Actual (material dan process cost) & $100 \%$ \\
\hline On Time Mold Finish & $100 \%$ \\
\hline Overtime ratio & $8 \%$ \\
\hline
\end{tabular}

Departemen Moldmaker berperan dalam membuat cetakan plastik ( mold) baru dan menjadi bagian penunjang dari departemen Research \& Development. Moldmaker harus dapat menjamin cetakan plastik yang dibuat dalam kondisi dan kualitas yang baik. Departemen 
Moldmaker masih bertanggung jawab atas cetakan plastik yang dibuatnya dimulai dari tahap pembuatan, tahap trial pertama dan tahap trial akhir untuk produksi massal. Setelah tahap produksi massal, cetakan plastik akan diserahkan ke departemen Mold Maintenance. Data di masa lampau yang digunakan adalah data selama tahun 2017 dan dibuat dalam poin- poin dengan menggunakan Balanced Scorecard berdasarkan 4 perspektif yang ada. Balanced Scorecard akan dibuat setiap bulan, dan terdapat beberapa poin yang harus diisi di dalam tabel Balanced Scorecard, yaitu:

1. Spot : Spot merupakan suatu angka dimana posisi perusahaan berada di bulan tersebut berdasarkan poin dalam perspektif yang dibuat.

2. YTD ( Year to Date) : YTD merupakan suatu angka akumulasi dimulai dari bulan awal tahun sampai dengan bulan pengisian Balanced Scorecard.

3. Target : Target merupakan batas yang telah ditetapkan oleh manajemen dimana diharuskan dicapai oleh departemen terkait.

4. Trend: Trend merupakan representatif dari nilai Spot dibandingkan dengan Target. Apabila Spot lebih rendah dibandingkan target, tanda panah akan menunjuk ke bawah dan menjadi indikasi harus dilakukan peningkatan dan perbaikan di bulan tersebut.

Berdasarkan hasil analisa dan pertimbangan perusahaan, didapat poin- poin yang akan dijadikan sebagai indikator penilaian dan juga target yang diberikan, yaitu sebagai berikut :

\section{Perspektif finansial}

Pada perspektif finansial, beberapa poin yang akan menjadi indikator antara lain :

1. Profit Loss per Project : merupakan perhitungan keuntungan atau kerugian dari setiap project. Keuntungan atau kerugian project dihitung dari nilai penjualan cetakan plastik dikurangi dengan biaya yang dibutuhkan untuk membuat cetakan plastik. Target yang diberikan adalah : 0

2. Back Log Project : merupakan perhitungan pekerjaan / project yang tertunda atau belum selesai di bulan atau tahun sebelumnya. Target yang diberikan adalah : 0

3. Order Intake : merupakan perhitungan permintaan pembuatan cetakan plastik yang diterima oleh departemen Moldmaker terhitung pada tahun finansial nya. Tidak ada target yang diberikan, semakin banyak semakin baik

4. Sales : merupakan perhitungan cetakan plastik yang berhasil dijual. Cetakan plastik baru dikategorikan terjual apabila cetakan plastik sudah dinyatakan layak untuk digunakan dalam produksi massal. Target yang diberikan adalah : Rp 100.000.000,00

\section{Perspektif pelanggan}

Pada perspektif pelanggan, beberapa poin yang akan menjadi indikator antara lain :

1. OTD T0 : OTD T0 merupakan singkatan dari On Time Delivery T0, merupakan suatu indikator apakah cetakan plastik yang dibuat di Moldmaker tepat waktu untuk dilakukan trial pertama ( T0 ) oleh departemen Research \& Development. Target yang diberikan adalah : $100 \%$

2. OTD Sales : OTD Sales merupakan singkatan dari On Time Delivery Sales, merupakan suatu indikator apakah cetakan plastik yang dibuat di Moldmaker tepat waktu untuk menghasilkan produksi massal sesuai jadwal dari departemen Research \& Development. Target yang diberikan adalah : $100 \%$

\section{Perspektif proses bisnis internal}

Pada perspektif proses bisnis internal, beberapa poin yang akan menjadi indikator antara lain:

1. Utilization : merupakan suatu angka utilitas dari mesin dalam persentase. Angka ini didapat dari hasil perhitungan jam mesin yang digunakan dibagi dengan jam mesin yang tersedia. Target yang diberikan adalah $40 \%$

2. Non Quality Cost : merupakan suatu biaya yang dikeluarkan oleh departemen Moldmaker, untuk melakukan pekerjaan berulang ( rework )bagi pekerjaan yang mengalami kesalahan ( defect ). Target yang diberikan adalah 0 
3. Overtime : merupakan suatu biaya yang dikeluarkan oleh departemen Moldmaker untuk memberikan upah tambahan bagi pekerja yang melakukan pekerjaan di luar jam bekerja. Target yang diberikan adalah $8 \%$

\section{Perspektif pembelajaran dan pertumbuhan}

Pada perspektif pembelajaran dan pertumbuhan, beberapa poin yang akan menjadi indikator antara lain :

1. Training Employee ( Technical ) : merupakan suatu angka jumlah jam pelatihan teknis yang wajib diikuti oleh karyawan di departemen terkait. Target yang diberikan adalah 8 jam.

2. Training Employee ( Non Technical ) : merupakan suatu angka jumlah jam pelatihan non teknis yang wajib diikuti oleh karyawan di departemen terkait. Target yang diberikan adalah 8 jam.

3. Turn Over Rate : merupakan suatu angka dalam persentase yang menunjukkan jumlah karyawan kunci yang keluar / mengundurkan diri dari departemen terkait. Target yang diberikan adalah $4 \%$ /

4. Head Count Personnel : merupakan suatu angka yang menunjukkan jumlah karyawan yang ada di departemen terkait. Target yang diberikan adalah 50 orang.

\begin{tabular}{|c|c|c|c|c|c|}
\hline \multicolumn{5}{|c|}{2018} & \\
\hline Customer Perspective & Spot & YTD & Target & Trend & \\
\hline OTD TO & & & $100 \%$ & $\rightarrow$ & \\
\hline OTD Sales & & & $100 \%$ & $\rightarrow$ & \\
\hline Financial Perspective & Spot & YTD & Target & Trend & \\
\hline Profit Loss per Project & & & 0 & $\rightarrow$ & \\
\hline Back Log Project & & & 0 & $\rightarrow$ & \\
\hline Order Intake & & & & $\rightarrow$ & \\
\hline Sales & & & Rp $100,000,000$ & $\rightarrow$ & \\
\hline Internal Business Process Perspective & Spot & YTD & Target & Trend & \\
\hline $\begin{array}{l}\text { Utilization (\%) } \\
\text { (1) }\end{array}$ & & & $40 \%$ & $\rightarrow$ & \\
\hline Non Quality Cost & & & $0 \%$ & $\rightarrow$ & \\
\hline Overtime & & & $8 \%$ & $\rightarrow$ & \\
\hline Learning \& Growth Perspective & Spot & YTD & Targe & & Trend \\
\hline Training Employee ( Technical ) & & & 8 & Hours & $\rightarrow$ \\
\hline Training Employee ( Non Technical) & & & 8 & Hours & $\rightarrow$ \\
\hline Turn Over Rate & & & $4 \%$ & & $\rightarrow$ \\
\hline Head Count Personnel & & & 50 & & $\rightarrow$ \\
\hline
\end{tabular}

\section{Gambar 2. Poin dan target di dalam Balanced Scorecard pada setiap perspektif}

Gambar 2 merupakan poin dan target yang dianalisa di dalam Balanced Scorecard. Prioritas dari evaluasi maupun perbaikan berfokus pada poin yang memiliki trend menurun, sedangkan untuk yang memiliki trend stabil atau meningkat tidak menjadi prioritas dalam evaluasi maupun perbaikan.

\section{KESIMPULAN}

Balanced Scorecard merupakan suatu metode pengukuran kinerja yang menilai kinerja perusahaan secara keseluruhan yang menggunakan 4 perspektif dengan mengacu terhadap visi maupun strategi perusahaan. Keempat perspektif yang digunakan sebagai tolak ukur kinerja adalah : ( 1 ) Perspektif finansial, ( 2 ) Perspektif pelanggan, ( 3 ) Perspektif proses 
bisnis internal , ( 4 ) Perspektif pembelajaran dan pertumbuhan. Poin dan target di masingmasing perspektif yang digunakan sebagai indikator penilaian di dalam Balanced Scorecard yaitu :

\section{Perspektif finansial}

Tabel 2. Poin \& target pada perspektif finansial

\begin{tabular}{|l|l|}
\hline \multicolumn{1}{|c|}{ Poin } & \multicolumn{1}{c|}{ Target } \\
\hline Profit Loss per Project & 0 \\
\hline Back Log Project & 0 \\
\hline Order Intake & \\
\hline Sales & $\mathrm{Rp} 100.000 .000,00$ \\
\hline
\end{tabular}

\section{Perspektif pelanggan}

Tabel 3. Poin \& target pada perspektif pelanggan

\begin{tabular}{|l|l|}
\hline \multicolumn{1}{|c|}{ Poin } & \multicolumn{1}{c|}{ Target } \\
\hline OTD T0 & $100 \%$ \\
\hline OTD Sales & $100 \%$ \\
\hline
\end{tabular}

\section{Perspektif proses bisnis internal}

Tabel 4. Poin \& target pada perspektif proses bisnis internal

\begin{tabular}{|l|l|}
\hline \multicolumn{1}{|c|}{ Poin } & \multicolumn{1}{c|}{ Target } \\
\hline Utilization & $40 \%$ \\
\hline Non Quality Cost & 0 \\
\hline Overtime & $8 \%$ \\
\hline
\end{tabular}

\section{Perspektif pembelajaran dan pertumbuhan}

Tabel 5. Poin \& target pada perspektif pembelajaran dan pertumbuhan

\begin{tabular}{|l|l|}
\hline \multicolumn{1}{|c|}{ Poin } & \multicolumn{1}{c|}{ Target } \\
\hline Training Employee (Technical) & 8 jam per tahun \\
\hline Training Employee (Non Technical) & 8 jam per tahun \\
\hline Turn Over Rate & $4 \%$ \\
\hline Head Count Personnel & 50 \\
\hline
\end{tabular}

Dengan menggunakan Balanced Scorecard, dapat dilihat keseimbangan kinerja yang harus dicapai dan dapat dianalisa bagian mana dari perspektif tersebut yang memerlukan perbaikan dan peningkatan dengan melihat trend yang ada di dalam penilaian Balanced Scorecard.

\section{DAFTAR PUSTAKA}

Aguinis, H. (2008). Performance Management ( 2nd ed.) . New York : Prentice Hall.

Gasperz, V. ( 2002 ). Sistem Manajemen Kinerja Terintegrasi BALANCED SCORECARD DENGAN SIX SIGMA UNTUK ORGANISASI BISNIS DAN PEMERINTAH . Jakarta : PT Gramedia Pustaka

Kaplan, R. S., \& Norton, D. P. (1996). The Balanced Scorecard: translating strategy into action.Boston: Harvard Business School Press.

Niven, P. R. ( 2006 ). BALANCED SCORECARD STEP-BY-STEP MAXIMIZING PERFORMANCE and MAINTAINING RESULTS ( 2nd ed. ). New Jersey : John Wiley $\&$ Sons, Inc. 
Jurnal Inkofar * Volume 1 No. 1, Juli 2018 * ISSN: 2615-3645 (Print) / 2581-2920 (Online)

Tersedia secara online di: http://www.politeknikmeta.ac.id/meta/ojs/

Nugrahayu, E. R. \& Retnani, E. D. ( 2015 ). PENERAPAN METODE BALANCED SCORECARD SEBAGAI TOLAK UKUR PENGUKURAN KINERJA PERUSAHAAN. Jurnal Ilmu \& Riset Akutansi Vol. 4 No. 10.

Solichah, A. D. , Dzulkirom, M. , \& Saifi, M. ( 2015 ). ANALISIS BALANCED SCORECARD SEBAGAI SARANA PENGUKURAN KINERJA PERUSAHAAN ( Studi Kasus pada Pabrik Gula Pesantren Baru Kediri ). Jurnal Administrasi Bisnis Vol. 27 No. 1.

Stevanovska, L. \& Soklevski, T. ( 2014 ) . Benefits of Using Balanced Scorecard in Strategic and Operational Planning . Universal Journal of Management 2(4) : 165-171 . 